\title{
Práticas de Professores Frente ao Aluno com Deficiência Intelectual em Classe Regular ${ }^{1}$ \\ Teachers' Pedagogical Practices With Students With Intellectual DisABILITY IN REGULAR CLASSROOMS
}

\author{
Teresa Cristina Coelho dos SANTOS 2 \\ Lúcia de Araújo Ramos MARTINS³
}

\begin{abstract}
RESUMO: este artigo detalha aspectos de uma pesquisa qualitativa, que teve por objetivo investigar práticas pedagógicas de professores em uma escola pública municipal de Natal/RN, frente a alunos com Deficiência Intelectual (DI), matriculados em anos iniciais do Ensino Fundamental. Foram utilizados como procedimentos a observação e a entrevista semiestruturada, com vistas à construção dos dados. Para análise dos dados utilizou-se o método de Análise de Conteúdo. Os resultados apontam práticas de docentes pautadas num fazer pedagógico tradicional, utilizando poucas estratégias que possibilitem avanços na aprendizagem desses alunos. Diante desta realidade, necessário se faz, entre outros aspectos: investimento na formação dos professores e de todos os que fazem a comunidade escolar, numa perspectiva inclusiva; utilização de procedimentos e de adequaçóes curriculares em sala de aula, de maneira mais compatível com as necessidades dos educandos; um trabalho em parceria com docentes de Salas de Recursos Funcionais e com as famílias.
\end{abstract}

PALAVRAS-CHAVE: Educação Especial. Práticas Pedagógicas. Inclusão Escolar. Deficiência Intelectual.

\begin{abstract}
This article details aspects of a qualitative study concerning teachers' pedagogical practices with Students with Intellectual Disability. The students considered in the study were enrolled in the first years of the Elementary School in a municipal school in Natal/RN. The data was collected through observation and semi structured interviews. The data analysis used the Content Analysis method. The results show that teacher practices are connected to traditional pedagogical behavior, which use few strategies that lead to advances in these children's learning. Given this reality, the following aspects need to be addressed: investments in teacher development, along with the members of school staff in light of the inclusive perspective; performance of procedures and adaptation of the classroom curriculum in order to make it more suitable to these students' needs; working in partnership with Resource classroom teachers and the student's families.
\end{abstract}

KEYWORDS: Special Education. Pedagogical Practices. School Inclusion. Intellectual Disability.

\section{INTRODUÇÁo}

O movimento em prol da inclusão de alunos com deficiências na classe comum, desencadeado a partir da última década do século vinte, vem provocando debates no meio escolar, assim como mudanças nas políticas e nas práticas de professores frente ao aluno com deficiência, entre os quais aqueles que apresentam Deficiência Intelectual (DI).

\footnotetext{
${ }^{1}$ http://dx.doi.org/10.1590/S1413-65382115000300006

${ }^{2}$ Assessora pedagógica da Secretaria Municipal de Educação de Natal/RN. Natal, RN, Brasil. teresaccoelho@yahoo.com.br

${ }^{3}$ Docente do Curso de Licenciatura em Pedagogia e do Programa de Pós-Graduação em Educação, Centro de Educação, Universidade Federal do Rio Grande do Norte. Natal, RN, Brasil. luc.martins@terra.com.br
} 
Um dos grandes desafios que se apresentam para a inclusão dos alunos com DI em salas comuns parte da própria escola e dos seus educadores que, muitas vezes, têm uma visão distorcida dessas crianças, percebendo-as como diferentes e entendendo que a tarefa de educá-las requer um conhecimento e uma experiência especial (MITTLER, 2003).

A forma de ver a deficiência prejudicou o inicio do processo de inclusão do aluno com DI, fortalecendo mitos sobre a sua aprendizagem, construídos socialmente a partir de atitudes preconceituosas e segregacionistas de educadores, pois o temor pela diferença permeou em grande parte a discriminação que afeta, muitas vezes, as escolas.

Gradativamente, mesmo com todas as dificuldades inerentes ao processo inclusivo, a prática docente com alunos com DI é algo que vem sendo construído gradativamente e, assim, "[...] a escola para todos extingue as práticas escolares onde todos os alunos têm de dominar as mesmas aprendizagens, no mesmo ritmo e através dos mesmos métodos de ensino". (PIRES, 2006, p.91)

Nesta perspectiva, algumas informaçóes são consideradas importantes para a prática pedagógica, com base nas seguintes indagações: o que ensinar? Quando ensinar? Como ensinar? Como e quando avaliar? Dessa forma, o professor terá condições de pensar numa prática pedagógica efetiva, levantando possibilidades de atuação, caso necessário.

$\mathrm{Na}$ escola atual, as práticas devem atender à diversidade da turma, independente da existência de alunos com deficiência ou não. Daí os procedimentos pedagógicos precisam ter um caráter flexível, diversificado, que envolvam todos os alunos da sala de aula, sem exceção.

Nesse sentido, a investigação ora relatada objetivou investigar práticas pedagógicas de professores de uma escola da rede municipal de Natal/RN, em 2011, frente a alunos com Deficiência Intelectual (DI), matriculados em anos iniciais do Ensino Fundamental. De forma mais específica, buscou: a) identificar a concepção que professores de uma escola municipal têm sobre Educação Inclusiva; b) conhecer a visão dos docentes sobre Deficiência Intelectual (DI) e sobre as possibilidades de aprendizagem de alunos com essa deficiência; c) analisar as práticas pedagógicas desenvolvidas pelos professores, identificando procedimentos que favoreçam a aprendizagem e inclusão dos alunos com Deficiência Intelectual (DI), de anos iniciais, em uma escola pública de Natal/RN.

\section{Método}

A presente pesquisa, aprovada pelo Comitê de Ética em Pesquisa da Universidade Federal do Rio Grande do Norte, com base no parecer no 020/2011, caracterizou-se como sendo de cunho qualitativo por "[...] contemplar uma metodologia de investigação que enfatiza a descrição, a indução, a teoria fundamentada e o estudo das percepçóes pessoais" (BOGDAN; BIKLEN, 1994, p.11).

Os procedimentos utilizados para a construção dos dados foram a observação e a entrevista semiestruturada. A observação realizada foi de caráter assistemático ou livre, buscando "[...] recolher e registrar fatos da realidade, sem que o pesquisador utilize meios técnicos especiais [...]” (MARCONI, 1996, p.81). Quanto à entrevista semiestruturada, consideramos 
que se constitui num dos principais meios que o investigador possui para realizar a coleta de dados, oferecendo perspectivas possíveis para que o entrevistado alcance a espontaneidade, enriquecendo a investigação (TRIVIÑOS, 1987). Para tanto, foi utilizado um roteiro de tópicos relativos à prática pedagógica desenvolvida, com perguntas abertas, dentro de uma conversação informal (MARCONI, 1996). As entrevistas foram gravadas em áudio e transcritas totalmente.

As análises das observações nos proporcionaram familiarização com o contexto, onde pudemos perceber aspectos marcantes da prática pedagógica e de como são tecidas as relaçôes entre professores e alunos com ou sem DI, no cotidiano escolar estudado. Para tanto, fizemos uma rotina de observaçáo, que nos permitiu estar na escola duas vezes por semana, numa média de três horas ao dia, durante os meses de junho a dezembro de 2011. Assim, conseguimos observar melhor alunos e docentes, não apenas durante as aulas, como também nos intervalos e nos momentos de recreio.

Os dados, considerando os procedimentos empregados, foram tabulados e analisados, com base na Análise de Conteúdo (BARDIN, 2010; FRANCO, 2008). Para tanto, seguimos os seguintes passos: a) transcrição, na íntegra, das falas dos sujeitos; b) procura de indicadores e pontos norteadores para interpretação dos dados; c) criação de categorias que, de certa forma, sistematizassem os dados, possibilitando a triangulação das falas dos sujeitos com os referenciais teóricos existentes sobre as temáticas (FRANCO, 2008). As categorias criadas emergiram do material analisado das entrevistas e das observaçóes das salas de aula dos professores colaboradores.

\subsection{Participantes}

Participaram do estudo duas professoras do Ensino Fundamental, atuantes nos anos iniciais ( $4^{\circ}$ e $5^{\circ}$ ano), de uma escola pública municipal, que tinham alunos com DI. Essas docentes estavam dentro da faixa etária compreendida entre 46 a 50 anos, tendo larga experiência de ensino. Uma delas era licenciada em Pedagogia, enquanto a outra cursava licenciatura em Letras. Como forma de manter o anonimato, resolvemos denominá-las de PROF1 e PROF2.

Atuavam em turmas que tinham uma média de 23 alunos, o que demonstrou estar em consonância com a legislação municipal vigente, que recomenda um máximo de 25 alunos na sala de aula e, neste contexto, até três alunos com algum tipo de necessidade educacional especial (NATAL, 2009).

A partir das informaçóes obtidas durante as entrevistas e observaçôes, constatamos que ambas não receberam qualquer informação e/ou orientação sobre como trabalhar pedagogicamente com alunos que apresentam deficiência, durante a formação inicial, mesmo a que estava ainda cursando uma licenciatura numa instituição particular de ensino superior. No entanto, apontavam esta preparaçáo, no decorrer da pesquisa, como sendo algo relevante para o desenvolvimento de uma ação pedagógica de qualidade com esses educandos.

\subsection{CaracterizaÇÃo da ESCOLA}

O estudo foi empreendido em 2011, em uma escola pública municipal localizada no bairro de Nazaré, situado na zona oeste da cidade de Natal/RN. A referida instituição foi 
fundada em outubro de 1988. Na ocasião da investigação, no turno matutino, 345 alunos estavam matriculados, distribuídos em 13 salas de aula de anos iniciais do Ensino Fundamental, existindo também uma sala destinada ao Atendimento Educacional Especializado (AEE), que funcionava desde 2004.

A escola, desde a sua criação, recebe alunos com as mais variadas necessidades educacionais especiais (NEE), sendo a Deficiência Intelectual (DI) a que prevalece. Constatamos que, dos 21 alunos com NEE então matriculados, 13 (61,9\%) eram registrados como alunos com DI, sendo duas no turno matutino ( $1^{\circ}$ ao $5^{\circ}$ ano) e 11 no turno vespertino $\left(6^{\circ}\right.$ ao $9^{\circ}$ ano).

\section{Resultados E Discussótes}

\subsection{CONCEPÇÓES DE EDUCAÇÃO INCLUSIVA FRENTE AOS ALUNOS COM DEFICIÊNCIA INTELECTUAL}

A partir dos depoimentos, podemos perceber que as professoras partícipes da pesquisa tinham maneiras diferentes de ver a educação inclusiva. Existiam duas formas de conceber a educação inclusiva, que estão expressas em suas falas:

PROF1: Como vou trabalhar com essas criaturas? Como vou fazer isso? Você coloca na sala de aula deficientes auditivos, surdos-mudos e coloca, um DI, coloca tudo misturado. [...] Eu achava melhor naquela época que tinha aquela sala especial [...] E, lá na sala especial, quando tinha sala especial, sempre aprendiam alguma coisa...

PROF2: Educação pra mim é tudo [...] há muito na teoria, mas na prática a gente não tem estrutura, nem condiçôes, tem muita boa vontade, está no caminho... Tem algumas coisas sendo trabalhadas...

A partir dos relatos das professoras, percebemos algumas divergências. Enquanto a PROF1 concebe a Educação Especial como uma mistura de alunos e se remete às denominadas classes especiais como uma modalidade educacional percebida como mais adequada a tais educandos, PROF2 - embora apresente certo pessimismo frente ao processo educacional ora desenvolvido - acredita que a educação inclusiva ainda está em processo, ou seja, está sendo construída. Em outras palavras, entende que embora não tendo sido implantada de maneira efetiva, pois as instituiçóes escolares ainda carecem de condiçóes pedagógicas e materiais para a sua real estruturação, já existem alguns aspectos sendo trabalhados nesse sentido.

Contudo, as participantes pontuam duas dificuldades, que consideram extremamente importantes: 1) a não preparação do sistema de ensino para atender aos educandos com deficiências; 2) a falta de estrutura escolar, principalmente relacionada ao pouco conhecimento dos profissionais da educação sobre as diversas deficiências e sobre as estratégias pedagógicas a serem utilizadas diante da diversidade do alunado, numa perspectiva inclusiva.

Consideramos que essa categoria é relevante porque a concepção de professores frente à educação inclusiva pode favorecer o sucesso ou o fracasso de alunos com deficiência intelectual na escola comum. 


\subsection{VISÁO SOBRE A DEFICIÊNCIA INTELECTUAL E POSSIBILIDADES DE APRENDIZAGEM}

Percebemos nos discursos das duas professoras pesquisadas, visóes diferentes acerca das possibilidades de aprendizagem de alunos com DI. Ficou evidente que uma delas detém uma visão tradicional de aprendizagem, bastante cristalizada, acreditando que problemas de memória, que percebe no aluno com DI, dificultam a retenção pelo mesmo do conteúdo trabalhado, prejudicando sensivelmente a sua aprendizagem:

PROF1: É um entrave... de não conseguir captar nada. E, às vezes, até que ele consegue captar, mas ele não consegue registrar [...] a questáo é a memória. A questáo da memória está envolvida na Deficiência Intelectual.

Predomina, nessa professora, uma representação social originada em uma abordagem centrada no déficit intelectual. Desta maneira, o aluno com DI é visto como um ser humano incompleto e com funcionamento deficitário (BEYER, 2005), dificultando muito ou até impossibilitando a sua aprendizagem no ambiente regular de ensino.

A segunda docente pesquisada, por sua vez, situa:

PROF2: Pra mim, como leiga, é essa dificuldade extrema que a pessoa tem de não assimilar esses conhecimentos intelectuais, cognitivos [...] Mas, no que diz respeito ao aluno deficiente intelectual, assim... Existe uma barreira quase intransponível para assimilar. [...] tem avanços, regressóes, avanços, regressóes... Assim, parece que a gente consegue alcançar...

Contudo, mesmo salientando inicialmente a grande dificuldade percebida nesses alunos, no tocante à aprendizagem, na continuidade da fala de PROF2 percebemos certo otimismo na visão de aprendizagem que os alunos com DI apresentam, a exemplo dos demais:

[...] eles aprendem... Não aprenderam a falar? Aprenderam a andar? A se comunicar? A se relacionar uns com os outros, com as pessoas? Não aprendem a conversar? Por que não aprendem a ler e escrever, também? A gente sabe que ler e escrever são uma (sic) coisa mais complexa e muito mais nova, porque a leitura e a escrita veio (sic) se massificar, agora, no século XX. Então, a gente vai descobrir um monte de deficiências nesta área. Mas, assim: vão aprender... Vão aprender, sim, não igual aos outros, mas no momento certo. Muitas vezes, dá um estalo... Lendo, como muitos... Quando via, os meninos estavam lendo... Tinham dificuldades, apenas, mas liam.

PROF2 evidencia acreditar que aprendizagem de alunos com DI pode acontecer, haja vista que, se eles aprenderam e aprendem outras coisas como, por exemplo, a falar, a andar, a se relacionar, entre vários aspectos, por que não podem avançar na aprendizagem da leitura e da escrita, também? Demonstra, no decorrer da sua fala, que a leitura é algo relativamente novo para a civilização. Podemos situar que é algo que representava um privilégio de uma elite e que, somente a partir de meados do século XX, passou a ser extensivo às pessoas em geral, em nosso país, embora seja relevante destacar que o quantitativo de analfabetos no Brasil, em pleno século XXI, ainda é muito expressivo.

Situa, ainda, que existe uma série de deficiências nessa área, no tocante às pessoas em geral, mas especialmente no que tange àquelas que apresentam deficiência intelectual. Entende 
que a aprendizagem é uma construção, que vai ocorrendo paulatinamente, de acordo com a singularidade de cada aluno.

É importante ressaltarmos que tal posicionamento não nega as dificuldades de aprendizagem do aluno com DI, porém, para PROF2 as limitaçôes desses alunos não podem servir de obstáculos para a sua aprendizagem.

Isto evidencia que não podemos nos guiar pela incapacidade e pelas limitaçôes dessas pessoas, como fatores determinantes, pois assim estaremos fortalecendo os processos de exclusão existentes. É preciso favorecer o seu desenvolvimento e, para tanto, as atividades escolares devem contribuir para superação das dificuldades.

Percebemos que PROF2 tem, gradativamente, absorvido novos paradigmas educacionais, a partir do modo de pensar sobre o que seria a deficiência intelectual. Sua visão está coerente com concepçóes de aprendizagem, nas quais todos, indistintamente, têm a capacidade de aprender. Isso nos conduz às reflexóes de Mantoan (1998, p. 8-9) sobre as reaçóes mentais de alunos com DI às solicitaçôes do meio escolar, quando assim se expressa:

[...] estudos comprovam que o subfuncionamento crônico da inteligência de pessoas com deficiência mental pode ser ativado por ajudas, visando proporcionar-lhes uma maior mobilidade cognitiva [...] buscando favorecer as habilidades intelectuais das pessoas com deficiência mental.

A autora também destaca as pesquisas de Borkowski e Pressley (1987) acerca de crenças motivacionais, cujas conclusóes indicam a necessidade de suscitar a motivação para se chegar aos resultados almejados. Para tanto, deve ser dada real importância ao aspecto motivacional, evitando bloqueios para a aprendizagem de alunos com DI na classe comum da escola regular.

O que constatamos nas duas professoras pesquisadas, a partir de seus discursos e nas observaçôes realizadas, foram visóes diferentes acerca das possibilidades de aprendizagem de alunos com DI. Ficou evidente que PROF1 detém uma visão tradicional, cristalizada de aprendizagem, enquanto que o depoimento de PROF2 está conectado ao paradigma da inclusão, com uma visão favorável ao aluno com DI no ambiente regular de ensino.

A crença na possibilidade de aprender, ou seja, no sucesso do aluno com Deficiência Intelectual, no tocante ao depoimento de PROF2, como vimos, estava atrelada à capacidade de perceber esse aluno como um ser com potencial para a aprendizagem, com capacidade de se desenvolver intelectualmente, de absorver aprendizagens mais complexas, como a leitura e a escrita, embora num ritmo próprio.

\subsection{Práticas pedagógicas de professores FRENTE a ALUNOS COM DeficiênCIA INTELECTUAL}

Com base em nossas observaçóes, priorizamos o registro escrito. Consideramos que as estratégias pedagógicas desenvolvidas pelas duas professoras se constituíram, principalmente, em aulas expositivas seguidas de exercícios escritos, utilizando quase sempre o quadro de giz, o que nos remete a uma prática pedagógica caracterizada por uma metodologia tradicional. Para 
Stainback, Stainback (1999), as estratégias para a promoção de práticas inclusivas nas escolas envolvem, fundamentalmente, a facilitação da mudança.

As estratégias pedagógicas são intrínsecas ao trabalho docente, que “[...] é uma atividade intencional, planejada conscientemente, visando atingir objetivos de aprendizagem" (LIBÂNEO, 1994, p.96). Deste modo, o ambiente pedagógico deve ser um espaço de fascinação, inventividade e prazer porque a aprendizagem é, antes de tudo, um processo corporal (ASSMANN, 2007).

Destacamos, porém, as idas à biblioteca, em que foram realizadas vivências de contação de histórias, mediadas pela professora da sala de aula e pela responsável pela biblioteca, o que favoreceu maior motivação dos alunos.

O que se observou foi que, mesmo que as professoras tenham utilizado alguns recursos visuais e mantido um diálogo com os alunos, durante as aulas de cunho expositivo, isso não foi suficiente para atrair a atenção dos educandos com deficiência intelectual. Entendemos que a aula expositiva poderia ser substituída por estratégias mais participativas, como os trabalhos em grupo, que - quando bem conduzidos - podem ser favorecedores de trocas de experiência e do desenvolvimento da cooperação entre seus integrantes.

Observamos, no tocante à PROF2, que alguns recursos visuais foram utilizados em sua turma, o que colaborou para criar uma interação mais forte entre alunos/professora, à medida que eram desenvolvidos os temas trabalhados, de forma mais acentuada do que em relação a PROF1. No entanto, as estratégias pedagógicas desenvolvidas por PROF2, embora tenham envolvido grande parte do alunado, não conseguiram motivar o aluno com DI, que demonstrou indiferença durante o desenvolvimento de muitas das atividades empreendidas com a turma.

Outro aspecto que consideramos merecer destaque diz respeito ao incentivo à participação dos alunos. Isto poderia ter acontecido de forma mais frequente, se trabalhos de grupo tivessem sido desenvolvidos, bem como se houvesse maior utilização de materiais que favorecessem a concretizaçáo de conteúdos ministrados. Para tanto, iriam requerer dos docentes um planejamento estratégico, com ênfase em práticas cooperativas, coletivas e diversificadas, com o intuito de envolver todos os alunos, favorecendo especialmente o trabalho entre pares (STAINBACK; STAINBACK, 1999; PACHECO, 2007; MANTOAN, 2000).

Nessa categoria, agregamos também adequaçóes curriculares como componentes da prática pedagógica, uma vez que "[...] os professores precisam modificar as atividades em que um determinado aluno participa, ou a maneira como ele atinge os objetivos" (STAINBACK; STAINBACK, 1999, p. 243).

Em se tratando de PROF1, percebemos que esta pontua dificuldades de realizar as adequaçóes em sua sala de aula, pois considera que a diversidade do alunado existente em sua turma se constitui num entrave. Segundo ela, é difícil lidar com alunos com Deficiência Intelectual, juntamente com alunos com problemas emocionais provocados por traumas, com alunos com fissura labiopalatal e com distorção idade/série.

Essa realidade, associada à carência de planejamento e à visão que apresenta a respeito das classes especiais ainda serem importantes para alunos com Deficiência Intelectual, está 
bem clara nas suas palavras, que podem ser vistas como um desabafo, ao ser questionada sobre adequaçóes curriculares:

Faço adequaçóes no ditado. Eu faço, pronto, pra eles faço só o ditado com três letras ou quatro letras, palavras mais simples. Já pros outros, não. Ai, eles perguntam: por que prá gente é diferente? Ai eles percebem. [...] Só não trabalhei com jogos. Vou ser sincera, não trabalhei porque, na minha sala, não dava. Pode até outro professor dizer assim: dava, mas eu sei como era minha sala. Por exemplo: se eu fosse trabalhar com jogos com eles e fosse dar o conteúdo aos outros que tinham necessidade de ter o conteúdo, eu não ia conseguir dar aula porque eles são muito inquietos. [...] (PROF1).

O discurso desta professora é marcado pela angústia de não poder fazer um trabalho melhor com a turma e ela parece se sentir insegura diante da situação exposta. $\mathrm{O}$ fato de não poder dar o conteúdo, de acordo com o nível da turma, a deixa ansiosa. Isso a faz ficar aflita, resultando numa atitude de impotência diante do alunado, principalmente, dos alunos com DI.

Quanto à PROF2, observamos que a forma de pensar a prática pedagógica tem um viés de inclusão, imbricada com adequaçóes curriculares. Sua fala demonstra simpatia à inclusão, assumindo-a como um desafio pedagógico:

Faço uma mistura de tudo. Vou observando o que dá certo, o que não dá certo. Às vezes, você faz uma..., planeja uma aula, acha que vai dar certo assim e, quando você vê, vai fazer em sala de aula, não é o momento certo para aquela aula, os alunos não se interessam. Eu fiz até um projeto de sala de aula, tenho uns livros em sala de aula, boto num varalzinho para pendurar as revistinhas em quadrinhos, os joguinhos. Aí, quando termina uma atividade, eu digo: olhe, não é obrigação, mas se quiserem [...]. Mesmo os que não sabiam ler pegavam um livro e ficavam. Ah, é assim: a questâo de motivaçáo para a leitura: querer aprender a ler. (PROF2).

A atitude pedagógica da professora, em relação à diversidade presente na sala de aula, a impulsiona a diversificar também as suas estratégias de ensino e, na simplicidade com que descreve os detalhes, podemos perceber um elo afetivo construído com a sua turma, ao longo do processo letivo.

Para Boneti (1997, p. 169-170), “[...] a adaptação do ensino [...], entre outros aspectos, significa alocar os recursos humanos na escola para trabalharem conjuntamente no sentido de desenvolver métodos e programas de ensino, adaptados a nova situação [...]”.

Ao analisarmos essa colocação de Boneti (1997), no que se refere às adequações curriculares, percebemos a sua importância para todos os alunos, pois são entendidas como um conjunto de estratégias que permitem a flexibilização do conteúdo de modo a possibilitar a todos a oportunidade de estabelecerem relaçóes com o saber (CARVALHO, 2008).

$\mathrm{Na}$ fala de PROF2, embora existam críticas ao tempo reduzido de planejamento dentro da escola, podemos perceber o esforço que faz para ampliá-lo, mesmo que isso implique em extrapolar o seu horário, levando afazeres pedagógicos para a sua casa. Portanto, essa forma de agir mostra o seu comprometimento com a turma, como manifesta em sua fala:

[...] você planeja, mas o planejamento é só o esqueleto, permite que elabore condiçóes para trabalhar em sala de aula. O planejamento é maravilhoso [...] não é suficiente, você dedicar um horário para só preparar material, preparar sua aula. $\mathrm{O}$ ideal seria o professor ter condiçôes de trabalhar só num horário e no outro preparar seu material, repensar seu trabalho, reavaliar, porque uma vez por semana você não consegue fazer isso, não, tem sempre aqueles percalços, 
sabe, você planeja uma coisa para a semana todinha e não dá certo, e só vai reavaliar na outra semana $[\ldots]$.

[...] faço às vezes coisa em casa, digito, eu penso o que vou fazer, vou anotando. Fico aqui até depois, aí vou recortar material, vou fazer alguma coisa, justamente pra... Imagine se eu trabalhasse os dois horários, porque eu faço em casa, vou digitando as atividades no computador, já penso uma atividade para Fulano e Sicrano, que está precisando disso e F, que náo enxerga direito. É desse jeito, tem que pensar em cada aluno. Você só vai conhecendo o aluno durante o processo, durante o ano.

PROF2 continua a relatar como trabalha com a turma em relação às adequaçóes curriculares, situando:

[...] quando dava Geografia, dava relevo. O que era relevo? Fazia desenho para ela. Montanha... Trabalhava a palavra montanha Se tivesse mais orientação eu podia fazer alguma coisa, além disso. Matemática, também trabalhava a soma, depois levava o material concreto para trabalhar com ela, a soma. Você precisa pensar para trabalhar individualmente com esses alunos, ter tempo para trabalhar com eles. Eu tinha vinte e três alunos, dois com diagnóstico e tinham outros que necessitavam de mais atenção, sem diagnóstico, duas alunas... Aluno, que percebi com problemas de vista; falei com mãe, fez o exame, mas veio fazer no final do ano e não comprou os óculos do menino; fazia, às vezes, a tarefa, quando dava os meus óculos. Mas não podia ficar emprestando meus óculos a ele, tinha $1,7^{\circ}$. Não enxergava nadinha, ficava o tempo todinho lá atrás... Não podia passar nenhuma atividade para ele, porque não enxergava...

Nesse sentido, com base nos discursos dos sujeitos, percebemos duas formas de se compreender as adequações curriculares. Acreditamos que PROF1 considera difícil incorporá-las à sua prática, uma vez que trabalha com um nível que requer mais conteúdos. Contudo, observamos que, em relação a PROF2, isso acontece com mais frequência, pois há uma flexibilização no modo como direciona o seu trabalho docente.

A partir das análises das falas e das observaçôes realizadas durante a nossa investigação, no contexto escolar, deduzimos que, embora não haja consenso na maneira de conduzir as adequaçóes curriculares, as professoras acham importantes a sua implementação como estratégia pedagógica, considerada enriquecedora da prática. Tudo isso numa perspectiva de diversificação das atividades, contemplando dessa forma, a diversidade da clientela. Assim, entendemos que diferenciar o ensino é

[...] fazer com que cada aprendiz vivencie, táo frequentemente quanto possível, situaçóes fecundas de aprendizagem [...] Para executar essa ideia simples, é preciso mudar profundamente a escola. Acrescentemos de imediato que adaptar a ação pedagógica ao aprendiz não e, no entanto, nem renunciar a instrui-lo, nem abdicar dos objetivos essenciais. Diferenciar é, pois, lutar para que as desigualdades diante da escola atenuem-se e, simultaneamente, para que o nível se eleve (PERRENOUD, 2000, p. 9).

Consideramos que ainda persiste um trabalho docente tecido no viés tradicional, embora, contrariamente a essa postura, tenhamos percebido nas professoras um desejo de mudança da prática pedagógica, o que representa uma perspectiva promissora. 
Ficou claro, no tocante às estratégias pedagógicas para atendimento à diversidade dos educandos, em particular para favorecer os alunos com Deficiência Intelectual, que urge a modernização do ensino, de modo que professores aperfeiçoem a sua prática, reestruturando as condiçóes atuais do ensino. Desta forma, a inclusão de pessoas com deficiência aconteceria naturalmente (MANTOAN, 1998).

Estratégias pedagógicas que favoreçam a inclusão de alunos com Deficiência Intelectual devem ser pensadas de maneira que beneficiem a todos, a fim de que as situaçóes de ensino sejam conduzidas para que os alunos possam

[...] ter acesso a todas as oportunidades educacionais e sociais oferecidas pela instituição escolar, este professor deve ter consciência de que o ensino tradicional deverá ser substituído por uma pedagogia de atenção à diversidade (FIGUEIREDO, 2009, p.42).

A esse respeito, dentre os estudos enfocando práticas pedagógicas com o aluno com deficiência e, de forma específica, com educandos com Deficiência Intelectual, achamos interessante pontuar alguns aspectos que emergiram dessa literatura. Sáo aspectos tidos como relevantes para a construção de práticas pedagógicas inclusivas, mesmo que tenham sido contemplados em tópicos precedentes neste trabalho, tais como: a valorização da diversidade leva em consideração que todos aprendem em tempos e em ritmos diferentes (BRASIL, 1997; 2004; STAINBACK; STAINBACK, 1999; LIMA, 2005); o desenvolvimento de atividades, tanto aquelas de sala de aula como as extraescolares contribuem para promover a participação e o engajamento de todos os alunos, considerando seus conhecimentos e suas vivências dentro ou fora do âmbito escolar (MANTOAN, 2009); o incentivo às práticas de amizade, com relação à maneira de como os alunos podem amadurecer juntos, trabalhando cooperativamente e cuidando uns dos outros, bem como participando da vida da escola (STAINBACK; STAINBACK, 1999; MITTLER, 2003); a construção de redes de apoio ou parcerias, com vistas a dar suporte aos professores que delas necessitem para melhor atuarem junto aos alunos com deficiência, assim como de parcerias escolares (STAINBACK; STAINBACK, 1999; MITTLER, 2003; MELO, 2008); a utilização de procedimentos bem desenvolvidos, que possibilitem uma avaliação satisfatória do progresso dos alunos (MITTLER, 2003); desenvolvimento de adequaçóes curriculares nas salas de aula, que consistem em modificaçóes realizadas nas estratégias que são intencionalmente organizadas pelos professores (CARVALHO, 2004; 2007; PACHECO, 2007).

Ressaltamos, também, a necessidade de se promover, paralelamente às estratégias citadas, uma maior parceria com os docentes atuantes nas Salas de Recursos Multifuncionais e um trabalho sistemático com a família, a qual deve se constituir, também, numa importante parceira nesse processo. Para tanto, consideramos de grande relevância a participaçáo dos pais no Conselho Escolar ${ }^{4}$. Acreditamos, também, que uma visão inovadora dada às práticas pedagógicas desenvolvidas no cenário escolar possibilitará maior motivação nos alunos em geral para uma efetiva aprendizagem.

\footnotetext{
${ }^{4}$ Conselho Escolar - órgão colegiado composto por representantes da comunidade escolar. [...] lugar de participação e decisão, um espaço de discussão, negociação das demandas educacionais [...] instância de discussão, acompanhamento e deliberaçăo, na qual se busca incentivar uma cultura democrática (BRASIL, 2004).
} 
Assim, esse fazer pedagógico para alunos com Deficiência Intelectual, na perspectiva da organização de um ambiente escolar inclusivo, considera as diferenças, garantindo a sua participação efetiva em todas as práticas educativas, favorecendo a atividade conjunta e a cooperação entre todos os alunos da sala de aula, que são participantes desse cenário escolar, criando novas expectativas de aprendizagem para todos.

\section{Conclusóes}

A pesquisa, que aqui relatamos, revelou aspectos relevantes da prática pedagógica desenvolvida por professores do Ensino Fundamental I, com turmas em que estavam matriculados alunos com DI.

Diante da realidade investigada, verificamos dificuldades situadas pelos docentes e observadas no cotidiano escolar, que se refletiram na ação docente desenvolvida, dentre as quais podemos citar: lacunas na formação relativas a uma fundamentação mais sólida sobre como lidar com as diferenças na sala de aula; persistência de uma visão clínica da deficiência; organização escolar estabelecida, muitas vezes dando pouca receptividade aos alunos considerados diferentes ou com deficiência, principalmente aqueles com DI; inexistência de redes de apoio ao trabalho com tais discentes, a não ser internamente, efetivada pela Sala de Recursos Multifuncionais; pouca participação dos pais na tomada de decisóes na escola, em todos os processos, como no Conselho Escolar e na construção do Projeto Político Pedagógico.

Para fins de nossa pesquisa, consideramos prática pedagógica como a ação desenvolvida na sala de aula, ou fora desta, em um processo de mediaçáo entre professor e aluno. Verificamos, portanto, que a prática pedagógica é concernente a uma interação próxima entre docente/discente, coerentemente ao que expõe Freire (1996): não há docência sem discência. Em decorrência dessa nova ação pedagógica, surge a necessidade de aquisição de conhecimentos teóricos e práticos, de cunho didático e pedagógico, sobre como trabalhar com alunos com DI, no cotidiano deste "protagonista" do processo educacional, em sala de aula: o professor.

Há uma necessidade premente de formação continuada para os professores e demais educadores que lidam, na escola, com a diversidade do alunado, incluindo neste contexto também os alunos com deficiência, uma vez que a formação sempre vai permear a prática pedagógica. Isso porque não basta somente a formação inicial, adquirida em cursos de licenciatura, uma vez que, além do aluno, há outro ser sempre aprendente na escola, que é o próprio professor. Por isso, este deve estar sempre conectado, em contínua formação, atento às transformaçóes que surgem e, neste sentido, ao novo modelo de escola inclusiva, ora estabelecido na política educacional.

Diante da realidade investigada, verificamos que muitas das dificuldades situadas pelos docentes e observadas no cotidiano escolar têm origem nas lacunas presentes na sua formação. Embora não existam receitas a serem seguidas, tal formação, se bem desenvolvida, contribuirá para uma mudança das práticas referentes ao ensino, no contexto da escola. Portanto, consideramos necessário que esse aperfeiçoamento profissional dê ênfase à dimensão subjetiva (humana), como forma de motivá-lo. 
Com relação à prática docente observada, constatamos que ainda prevalece uma prática de cunho tradicional, voltada para uma pedagogia transmissiva, com poucas adequaçóes curriculares, embora haja na escola a disponibilidade de material pedagógico e tecnológico, que, caso fosse mais utilizado, poderia contribuir significativamente para a aprendizagem de todos os alunos.

Nesse sentido, buscamos refletir sobre os principais aspectos colocados durante o processo de pesquisa referente à prática pedagógica, a partir de constatações no ambiente escolar, do qual levantamos algumas preocupações: as concepçóes dos professores sobre a DI e as possibilidades de aprendizagem para alunos com essa deficiência variam de um sujeito para outro. Enquanto uma das docentes pesquisada vê possibilidades de aprendizagem do aluno com DI e acredita na educação inclusiva - embora ainda fazendo algumas ressalvas à situação vivenciada - a outra está presa a uma visão tida hoje como ultrapassada, pois entende que somente nas classes especiais, anteriormente existentes, poderia ser desencadeada uma aprendizagem efetiva para os alunos com Deficiência Intelectual. Tal constatação demonstra que as concepções sobre DI ainda estão bastante ligadas à ideia de limitaçôes, de dificuldades extremas e à falta de algo.

Verificamos que a aceitação dos alunos com deficiência pelos seus colegas de sala e pelos alunos da escola, em geral, efetuava-se de maneira normal. Não notamos, de forma clara, problemas de rejeição em relação aos alunos com DI durante as aulas, nas salas observadas, o que é algo positivo, embora em uma das turmas existisse certo isolamento da aluna com DI durante algumas atividades. Isto precisaria ser mais bem trabalhado pela professora e demais integrantes da comunidade escolar, no sentido de derrubar algumas barreiras atitudinais que porventura ainda existam.

Diante do exposto, podemos afirmar que o processo de mudança, instaurado com a proposta da inclusão escolar, aponta para o estabelecimento de açóes compartilhadas, articuladas na escola, que podem fortalecer as práticas pedagógicas no sentido da construção de uma escola de qualidade para todos os alunos. Isto requer um fazer pedagógico que seja mais atraente e inovador, que seja adequado às especificidades e necessidades dos educandos, assim como que se acredite em uma aprendizagem significativa para todos os alunos da escola, sem distinção.

\section{REFERÊNCIAS}

ASSMANN, H. Reencantar a educação: rumo à sociedade aprendente. Rio de Janeiro: Vozes, 2007.

BARDIN, L. Análise de Conteúdo. São Paulo: Loyola, 2010.

BEYER. H.O. A educação Inclusiva: ressignificando conceitos e práticas da Educação Especial. Revista da Educação Especial, Brasília, DF, v.1, 2005.

BOGDAN, R.; BIKLEN, S. Investigação qualitativa em educação. Porto: Porto Editora, 1994. 
BONETI, R.V.F. O papel da escola na inclusão social do deficiente mental. In: MANTOAN, M.T.E. (Org.). A integração de pessoas com deficiência: contribuiçôes para uma reflexão sobre o tema. São Paulo: Memnon Editora, 1997. p.167-173.

BRASIL. Escola inclusiva: reorganização do trabalho pedagógico. Porto Alegre: Mediação, 2008.

BRASIL. Ministério da Educação. Parâmetros curriculares nacionais: introdução aos parâmetros curriculares nacionais. Brasília, DF: MEC/SEF, 1997.

BRASIL. Ministério da Educação. Secretaria de Educação Básica. Conselhos escolares: democratização da escola e construção da cidadania (Caderno 1). Brasília, DF: MEC/SEB, 2004.

BRASIL. Removendo barreiras para a aprendizagem: educação inclusiva. Porto Alegre: Mediação, 2007.

CARVALHO, R.E. Educação Inclusiva: com os pingos nos “is”. Porto Alegre: Mediação, 2004.

FIGUEIREDO, R.V. A formação de professores para a inclusão de alunos no espaço pedagógico da diversidade. In: MANTOAN, M.T.E. O desafio das diferenças nas escolas. Rio de Janeiro: Vozes, 2009.

FRANCO, M. L. P. B. Análise de Conteúdo. 3.ed. Brasília, DF: Liber Livro, 2008.

FREIRE, P. Pedagogia da Autonomia. São Paulo: Paz e Terra, 1996.

LIBÂNEO, J. C. Didática. São Paulo: Cortez, 1994.

LIMA, E.S. Diversidade e Aprendizagem. São Paulo: Sobradinho, 2005.

MANTOAN, M.T.E. Caminhos pedagógicos da inclusão: a formação do professor tal como a concebemos e realizamos. São Paulo: UNICAMP, Laboratório de Estudos e Pesquisa em Ensino e Reabilitação de Pessoas com Deficiência - LEPED, [1998].

MANTOAN, M.T.E. Educação escolar de deficientes mentais: problemas para a pesquisa e o desenvolvimento. Caderno CEDES. 1998, v.19, n.46. Disponível em: <http:/www.scielo.br/scielo. php?script=sci_arttext\&pid=S0101-32621998000300009\&lng=en\&nrm=iso\&tlng=pt $>$. Acesso em: 30 jul.2011.

MANTOAN, M.T.E. O desafio das diferenças nas escolas. Rio de Janeiro: Vozes, 2009.

MANTOAN, M.T.E. Todas as crianças são bem-vindas à escola. São Paulo: UNICAMP, Laboratório de Estudos e Pesquisa em Ensino e Reabilitação de Pessoas com Deficiência - LEPED, 2000.

MARCONI, M.A. Técnicas de Pesquisa. 3.ed. São Paulo: Atlas, 1996.

MELO, F.R.L.V. de. Atendimento educacional do aluno com paralisia cerebral: uma experiência de formação continuada. João Pessoa: Editora Universitária da UFPB, 2008.

MITTLER, P. Educaçâo inclusiva: contextos sociais. Porto Alegre: Artmed, 2003.

NATAL. Resolução No 05/2009. Disponível em: <http://www.natal.rn.gov.br/_anexos/publicacao/dom/ dom_20100128.pdf>. Acesso em: 27 jun. 2011.

PACHECO, J. Caminhos para a inclusão: um guia para o aprimoramento da equipe escolar. São Paulo: Artmed, 2007.

PERRENOUD, P. Pedagogia diferenciada: das intençôes à ação. Porto Alegre: Artmed, 2000. 
PIRES, J. A questão ética frente às diferenças: uma perspectiva da pessoa como valor. In: MARTINS, L.A.R. et al. (Org.). Inclusão: compartilhando saberes. Petrópolis: Vozes, 2006. p.78-94.

STAINBACK, S; STAINBACK, W. Inclusão: um guia para educadores, Porto Alegre: Artmed, 1999.

TRIVIÑOS, A.N.S. Introdução à pesquisa em ciências sociais: a pesquisa qualitativa em educação. São Paulo: Atlas, 1987.

Recebido em: 25/10/2014

Reformulado em: 16/05/2015

Aprovado em: 08/09/2015 